\title{
A Política de Circuitos Turísticos de Minas Gerais: Uma Avaliação baseada na Percepção de Agentes Estratégicos
}

\section{Fernanda Cristina da Silva; Afonso Augusto Teixeira de Freitas de Carvalho Lima; Suely de Fátima Ramos Silveira; Magnus Luiz Emmendoerfer ${ }^{i}$}

Universidade Federal de Viçosa (Brasil)

Antônio Artur de Souza ii

Universidade Federal de Minas Gerais - UFMG (Brasil)

Maria das Dores Saraiva de Loreto ${ }^{\text {iii }}$

Universidade Federal de Viçosa (Brasil)

\begin{abstract}
Resumo: O objetivo deste estudo, de natureza descritiva, é avaliar a Política de Circuitos Turísticos de Minas Gerais, considerando a percepção de agentes estratégicos. Os meios de investigação foram: pesquisa documental, bibliográfica e de levantamento. Os dados foram coletados através da aplicação de 37 questionários e analisados por meio da Análise de Conteúdo. Conforme os entrevistados, o principal resultado favorável da Política foi a integração dos municípios para planejar o desenvolvimento turístico da região, enquanto que o desfavorável está associado à sustentabilidade financeira dos circuitos, o que também se traduz na principal dificuldade na implementação da Política. Apesar dos desafios, existem perspectivas de continuidade da Política, considerando sua capacidade de potencializar atrativos turísticos e de mobilizar recursos financeiros e humanos.
\end{abstract}

Palavras-chave: Políticas Públicas; Políticas Públicas de Turismo; Política de Circuitos Turísticos; Turismo; Circuitos Turísticos

Title: The Touristic Circuit Policy of Minas Gerais: Evaluation Based in the Strategic Agents Perception

\begin{abstract}
This descriptive study aims to evaluate the Touristic Circuit Policy, considering the strategic agents perception. The research methods used were: survey, documental and bibliographic research. Data were collected through questionnaires applied in 37 circuits and analyzed through content analysis. According to respondents, the main favorable result of the policy was the integration of the cities to plan the touristic development of the region, whereas the main unfavorable is associated with the financial sustainability of the circuits, that expresses the main difficulty in the implementation of the policy. Although the challenges, there is a perspective of continuity of the policy, considering its capacity of potentiate touristic attractiveness and of mobilize and financial and human resources..
\end{abstract}

Keywords: Public Policy; Tourism Public Policy; Touristic Circuit Policy; Tourism; Touristic Circuit.

\footnotetext{
i Departamento de Administração e Contabilidade. Universidade Federal de Viçosa - UFV. E-mail1: fernanda.cristina@gvmail.br; Emai12: afonsoli@ufv.br; E-mail3: sramos@ufv.br; E-mail4: magnus@ufv.br

ii Departamento de Ciências Contábeis. Universidade Federal de Minas Gerais - UFMG. E-mail: artur@face.ufmg.br

iii Departamento de Economia Doméstica. Universidade Federal de Viçosa - UFV. E-mail: mdora@ufv.br
} 


\section{Introdução}

Nos últimos anos, o turismo no Brasil vem apresentando importantes resultados econômicos, sendo considerado um dos setores com maior capacidade de gerar divisas para o país, além de prover a uma grande parcela da população emprego e renda. Conforme dados divulgados pelo Banco Central (BC), o ano de 2010 registrou a entrada recorde de US\$ 5,919 bilhões em divisas no Brasil, por meio dos gastos de turistas estrangeiros. O valor é $11,58 \%$ superior ao registrado em 2009, quando US $\$ 5,3$ bilhões ingressaram no país pelo turismo internacional (MINISTERIO DO TURISMO - MTUR, 2011).

Não obstante, com o crescimento do setor turístico, muitos destinos começam a enfrentar os impactos negativos decorrentes da atividade, como, por exemplo, o turismo predatório. Além disso, outros problemas comumente enfrentados pelas localidades são a falta de recursos financeiros e humanos destinados especificamente ao desenvolvimento da atividade, e a dificuldade de conscientização das pessoas sobre a importância do setor, bem como de sua potencialidade para gerar formas alternativas de renda.

Nesse cenário, para minimizar os problemas apontados, denota-se a importância de políticas públicas voltadas para o planejamento do turismo, as quais, segundo Barretto, Burgos e Frenkel (2003:33) tem o papel de propiciar o desenvolvimento harmônico da atividade. Para os autores, cabe ao Estado a construção de infra-estrutura básica urbana e de acesso, e o oferecimento de um aporte jurídico-administrativo para planejar e controlar os investimentos que o governo realiza, de forma a garantir que estes retornem na forma de benefícios para a sociedade.

No Brasil, a gestão das políticas públicas de turismo tem ocorrido de forma descentralizada, sobretudo a partir de 2003, ano de criação do Ministério do Turismo, do Primeiro Plano Nacional de Turismo - PNT, para o período de 2003 a 2007, e do Programa de Regionalização do Turismo, o qual ainda hoje representa um dos principais programas de governo para o desenvolvimento do turismo em todo território nacional. Entre os Estados que adotam a gestão descentralizada do turismo destaca-se Minas Gerais, que, mesmo antes da criação do Programa de Regionalização do Turismo no Brasil, já implementava este modelo.

Como forma de atuação, o Governo de Minas, por meio de sua Secretaria de Turismo- SETUR, criou, em 2001, os chamados "circuitos turísticos". Estes se constituem basicamente em arranjos associativos de municípios, podendo ser compostos também pela iniciativa privada e pela sociedade civil. Salienta-se que os circuitos turísticos também se constituem em uma política própria - a Política de Circuitos Turísticos e representa uma das principais linhas de atuação para o desenvolvimento do turismo em Minas Gerais.

Denota-se que a Política de Circuitos Turísticos, desde a sua criação, tem sido considerada uma boa alternativa de gestão, tendo em vista que o Governo de Minas cada vez mais tem incentivado a criação de circuitos, considerando que estes possuem mais condições de trabalhar o desenvolvimento regional, tanto por estarem mais próximos da realidade, quanto por possuírem mais condições de atender as demandas existentes, considerando as especificidades de cada região. Além disso, por anteceder a implementação do modelo de gestão descentralizada e regionalizada à maioria dos Estados brasileiros, a referida Política também pode ser considerada inovadora.

Contudo, Beni (1998) chama a atenção para as fragilidades que o modelo de gestão regionalizada pode trazer, sobretudo com relação à incapacidade institucional para a gestão do turismo em muitas regiões, dadas as dificuldades dos estados e municípios em avaliar o alcance do seu objetivo principal, bem como em compreender e operacionalizar as proposições das diretrizes nacionais.

Dessa forma, apesar do otimismo com relação ao Programa de Regionalização e, especificamente, da Política de Circuitos Turísticos, que constantemente tem recebido prêmios por parte do Ministério do Turismo pela referência em gestão pública do turismo, torna-se instigante investigar se esta Política tem, de fato, apresentado resultados que condizem com os propósitos para qual ela foi criada. Sendo assim, o presente artigo tem por objetivo avaliar os resultados da Política de Circuitos Turísticos de Minas Gerais, considerando a percepção de agentes estratégicos, quais sejam aquelas pessoas diretamente envolvidas com a gestão do circuito.

\section{Referencial Teórico}

\section{Definição de Turismo}

De acordo com estudos da Fundação João Pinheiro FJP (2009:17), na pesquisa intitulada "Impactos do Turismo nas Finanças Municipais nas Regiões Turísticas do Brasil o significado do termo turismo está relacionado às viagens que jovens ingleses aristocratas realizavam no continente europeu na segunda metade do século XVIII, conhecidas como Grand Tour. Em virtude dessa denominação, os jovens que faziam essa viagens ficaram conhecidos como touristes.

Conforme Beni (1998), no campo acadêmico, nas empresas e nos órgãos governamentais, pode-se identificar três tendências para a definição de Turismo: a econômica, que somente reconhecem as implicações econômicas ou empresariais do turismo; a técnica, que se constrói a partir da definição particular de "turista" para, depois, se estendida ao turismo em geral; e a holística, que procura abranger a essência total do assunto.

$\mathrm{Na}$ tentativa de criar um marco conceitual para o turismo, a OMT - Organização Mundial do Turismo, desde a Conferência Internacional sobre Estatísticas de Viagens e Turismo, ocorrida em julho de 1991, em Ottawa - Canadá, define turismo como: “(...) todas as atividades que as pessoas realizam durante suas viagens e estadas em lugares diferentes do seu habitual, por um período consecutivo inferior a um ano, com a finalidade do ócio, negócios e outros motivos" (OMT, 2001:38). 
Segundo o referido órgão, esta definição é ampla e flexível e concretiza as características mais importantes do turismo, quais sejam: a introdução de elementos motivadores de viagens (lazer, negócios ou outros); nota temporária inferior a um ano para delimitar o que se considera habitual e delimitação da atividade desenvolvida antes e durante o período de estada; e localização da atividade turística em algum lugar fora do entorno habitual (OMT, 2001)

No Brasil, a Empresa Brasileira de Turismo - EMBRATUR considera que o turismo pode ser entendido como um "conjunto de relações e fenômenos produzidos pelo deslocamento e permanência de pessoas fora do lugar de domicílio, desde que tais deslocamentos e permanência não estejam motivados por uma atividade lucrativa" (MTUR, 2011:03)

É importante ressaltar que, apesar das particularidades das definições existentes sobre turismo, todas consideram os seguintes aspectos: o movimento físico dos turistas; a não permanência do turista no destino; tanto o deslocamento até o destino quanto as atividades realizadas durante a estada; e, por fim, os serviços e produtos criados para satisfazer as necessidades dos turistas (OMT, 2005).

Ainda segundo a OMT (2001, p. 39): a "natureza da atividade turística é um conjunto complexo de inter-relações de diferentes fatores que devem ser considerados conjuntamente". Assim, o turismo pode ser entendido como um sistema dinâmico composto por quatro elementos básicos da atividade turística que se interrelacionam, quais sejam: demanda - formada por um conjunto de consumidores reais ou potenciais de bens e serviços turísticos; oferta - conjunto de produtos, serviços e organizações envolvidas ativamente na experiência turística; espaço geográfico - base física na qual tem lugar a conjunção ou o encontro entre a oferta e a demanda e em que se situa a população residente e operadores de mercado - empresas e organismos cuja principal função é facilitar a interrelação entre a oferta e a demanda.

\section{Políticas Públicas de Turismo}

Definir políticas públicas, na visão de Fernandes (2007), é compreender o processo de produção de bens e serviços que gerem bem estar à população por parte do Estado. Para Saravia (2006), a política pública "trata-se de um fluxo de decisões públicas, orientado a manter o equilíbrio social ou a introduzir desequilíbrios destinados a modificar essa realidade". Para a autora, essas decisões são consideradas estratégias direcionadas aos vários fins desejados pelos tomadores de decisão.

Na visão de Cruz (2001:40), uma política pública de turismo pode ser definida como um "conjunto de intenções, diretrizes e estratégias estabelecidas e/ou ações deliberadas, no âmbito do poder público, em virtude do objetivo geral de alcançar e/ou dar continuidade ao pleno desen- 


\section{Avaliação de Políticas Públicas}

Para Faria (2003, p. 44-45), a avaliação pode ser definida como

atividade destinada a aquilatar os resultados de um curso de ação cujo ciclo de vida se encerra; a fornecer elementos para o desenho de novas intervenções ou para o aprimoramento de políticas e programas em curso; e como parte da prestação de contas e da responsabilização dos agentes.

Conforme Draibe (2001), a avaliações de políticas e programas respondem a distintos objetivos, tais como: conhecer a relação entre condições, meios, resultados e impactos da intervenção; verificar a eficácia, a eficiência e a accountability das ações; verificar se os objetivos mais imediatos foram alcançados, de forma a corrigir os rumos do programa ou disseminar lições e aprendizagens; e detectar obstáculos e propor medidas de correção e alteração de programas, visando à melhoria da qualidade do seu processo de implementação e do desempenho da política.

Para Cohen e Franco (2004), a avaliação pode ser classificada com base em dois critérios: quanto ao momento em que a avaliação vai ocorrer; e quanto ao enfoque ou problema que se pretende responder. Com relação ao primeiro critério, a avaliação pode ser classificada como ex-ante, quando é realizada no início do programa ou na sua formulação, objetivando um diagnóstico que visa dar suporte à decisão de implementar ou não um determinado programa; e ex-post, quando, geralmente, é feita ao término do programa com objetivo de medir os resultados alcançados.

Com relação ao critério do problema a ser solucionado, a avaliação pode ser classificada em dois tipos básicos: avaliação de processos e avaliação de impactos. A avaliação de processo é realizada durante a implementação e tem como principal finalidade oferecer subsídios para a gestão. Já a avaliação de impacto busca responder se o programa ou política teve ou não resultado, sendo realizada ao final do programa (COHEN E FRANCO, 2004).

Costa e Castanhar (2003) corroboram a classificação apresentada por Cohen e Franco (2004) e acrescentam um outro tipo de avaliação referente a esse critério, qual seja a avaliação de metas, que tem por objetivo medir o grau de êxito que um programa obtém em relação ao alcance de metas previamente estabelecidas.

Alguns aspectos que funcionam como indicadores gerais de avaliação de resultados de programas e políticas são a eficiência, eficácia e efetividade (BELLONI, 2003). A UNICEF (1990), citado por Costa e Castanhar (2003:973), define eficiência como "menor relação custo/benefício possível para o alcance dos objetivos estabelecidos no programa"; eficácia como a "medida do grau em que o programa atinge os seus objetivos e metas"; e impacto (ou efetividade) como a medida que "indica se o projeto tem efeitos (positivos) no ambiente externo em que interveio, em termos técnicos, econômicos, socioculturais, institucionais e ambientais".

\section{Metodologia}

O presente estudo pode ser classificado como uma pesquisa descritiva, uma vez que busca descrever a percepção de agentes estratégicos sobre os resultados da Política de Circuitos Turísticos. Quanto aos meios de investigação, o estudo pode ser classificado como uma pesquisa de levantamento, pois, para a coleta de dados, foram aplicados questionários junto aos agentes estratégicos dos circuitos, quais sejam os gestores e/ou dirigentes destes, e, ainda, como documental, uma vez que foram considerados, para a caracterização da Política, documentos institucionais disponibilizados pela Secretaria de Turismo de Minas Gerais - SETUR.

O universo da pesquisa compreendeu os 38 circuitos turísticos de Minas Gerais certificados até o ano de 2008, exceto 01, por apresentar peculiaridades que o diferenciam dos demais. Sendo assim, a pesquisa contou com respostas de 37 questionários, sendo que destes, 33 foram aplicados durante visitas de campo no circuito e 04 viaemail, uma vez que os respondentes não tiveram disponibilidade para atender os pesquisadores.

Dos respondentes, $27(72,97 \%)$ assumiam a função de gestores; 4 (10,81\%) de presidentes; $2(5,41 \%)$ de presidentes que também assumiam o cargo de gestores; 2 (5,41\%) de membros da diretoria; 1 (2,70\%) de secretário; e $1(2,70 \%)$ de turismólogo. Salienta-se que foi priorizada a aplicação dos questionários junto aos gestores; mas, em casos de circuitos com ausência desses, priorizou-se os responsáveis pela gestão dos circuitos.

Os documentos analisados foram o Decreto-Lei 43321, de 08/05/2003, que dispõe sobre o reconhecimento dos Circuitos Turísticos e a Resolução Setur n. ${ }^{\circ} 008$, de 28/03/2008, que estabelece normas relativas ao "Certificado de Reconhecimento" dos Circuitos Turísticos do Estado de Minas Gerais. Além disso, foram analisadas informações constantes no site institucional da SETUR.

Salienta-se que o recorte temporal de 2008 deve-se ao próprio objetivo de pesquisa, que implica em selecionar circuitos que possuam resultados passíveis de serem avaliados, demandando para tal uma maior estruturação. Dessa forma, a partir de conversas exploratórias e da aplicação de questionário, que contemplava informações preliminares sobre os circuitos, considerou-se que aqueles que possuíam pelo menos dois anos de existência, considerando como base a data de coleta de dados - julho e agosto de 2010, já poderiam apresentar algum tipo de resultado.

Os dados foram tratados por meio de uma abordagem qualitativa, utilizando-se da técnica de Análise de Conteúdo, que segundo Bardin (2002:34), corresponde a "um conjunto de técnicas de análise das comunicações, que utiliza procedimentos sistemáticos e objetivos de descrição do conteúdo das mensagens". Para a autora, a intenção desta análise é obter indicadores (quantitativos ou não), que permitam a inferência de conhecimentos sobre o conteúdo das mensagens.

Ainda segundo Bardin (2002), o primeiro passo desta análise é chamado de "análise categorial", a qual busca 
classificar o conteúdo do texto (considerado em sua totalidade), segundo a freqüência da presença ou da ausência de elementos de significação. Estes elementos são denominados de "unidades de codificação" ou de "registro" e correspondem, por exemplo, a uma frase ou uma palavra. Definir estas unidades "consiste em classificar os diferentes elementos nas diversas gavetas segundo critérios susceptíveis de fazer surgir um sentido capaz de introduzir certa ordem na confusão inicial" (BARDIN, 2002:37).

Ressalta-se que nas análises, os respondentes foram codificados com a letra $\mathrm{C}$, seguido do número da entrevista (C1, C2 ... C37). A seguir, apresenta-se uma síntese dos procedimentos metodológicos adotados neste estudo (Figura 1).

\section{Minas Gerais.}

A primeira ação do Governo de Minas Gerais para legitimar os circuitos turísticos ocorreu em 2003, com a instituição do Decreto-Lei 43.321, de 08/05/2003, que dispõe sobre o reconhecimento dos circuitos e dá as coordenadas para tal.

Conforme este Decreto, os circuitos turísticos são definidos como um

conjunto de municípios de uma mesma região, com afinidades culturais, sociais e econômicas que se unem para organizar e desenvolver a atividade turística regional de forma sustentável, através da integração contínua dos municípios, consolidando uma atividade

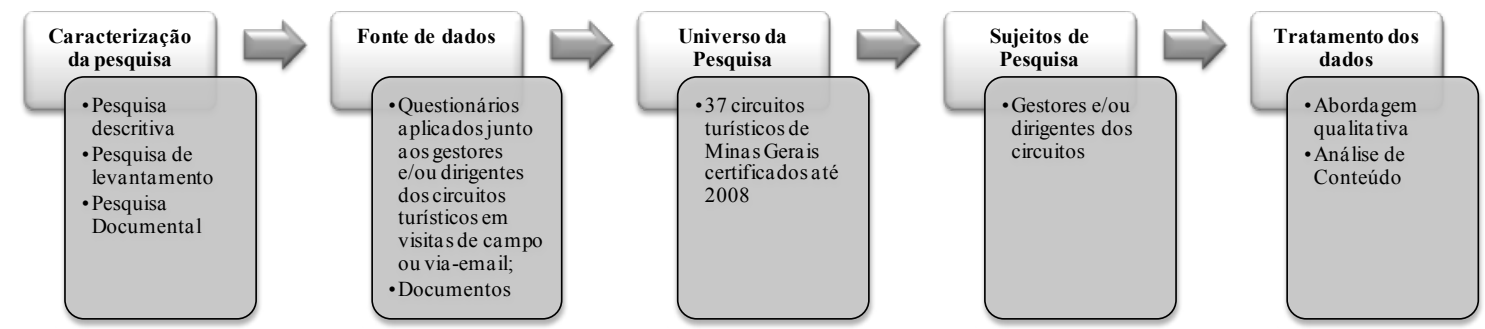

Figura 1: Síntese dos procedimentos metodológicos da pesquisa. Fonte: Elaborado pelos autores

\section{Apresentação e Análise dos Resultados}

Para atingir o objetivo geral deste estudo, a seguir, apresenta-se a caracterização da Política de Circuitos e posteriormente a avaliação dos seus resultados. Para tanto, conforme Quadro 2, foram criadas duas categorias: Categoria 01 - Caracterização da Política de Circuitos Turísticos, a qual não conta com subcategorias; e Categoria 02 - Avaliação da Política, que contem as seguintes subcategorias: Resultados Favoráveis; Resultados Desfavoráveis; Dificuldades na Implementação da Política; e Propostas de Soluções para Sanar as Dificuldades.

Categoria 01 - Caracterização da Política de Circuitos Turisticos

A presente categoria tem por objetivo apresentar a caracterização legal da Política de Circuitos Turísticos de regional (MINAS GERAIS, 2010).

Ademais, o referido Decreto também determina que para fins de promoção da Política de Circuitos no âmbito estadual, os circuitos institucionalizados e com personalidade jurídica devem receber um "Certificado de Reconhecimento" a ser expedido pela SETUR. Sendo assim, somente os circuitos com esse certificado podem participar da Política.

De acordo com a Resolução Setur n. ${ }^{\circ} 008$, de 28/03/2008, para receber esse certificado os circuitos turísticos devem contar com pelo menos um ano de existência formal e serem constituídos por, no mínimo, 05 municípios, além de apresentar uma série de documentos institucionais (como estatuto, e CNPJ) e de operacionalização dos circuitos (como plano de ações e relatórios de trabalho), bem como cumprir exigências estatutárias e diretrizes básicas previstas nesta resolução.

\begin{tabular}{|c|c|c|}
\hline Categorias & Subcategorias & Fonte de dados \\
\hline $\begin{array}{c}\text { Caracterização da Política de } \\
\text { Circuitos Turísticos }\end{array}$ & --- & $\begin{array}{c}\text { Documentos e site da SETUR } \\
\text { (www.turismo.mg.gov.br/) }\end{array}$ \\
\hline \multirow{4}{*}{$\begin{array}{l}\text { Avaliação da } \\
\text { Política }\end{array}$} & Resultados Favoráveis & \multirow{4}{*}{$\begin{array}{l}\text { Questionários (percepção } \\
\text { dos agentes estratégicos) }\end{array}$} \\
\hline & Resultados Desfavoráveis & \\
\hline & $\begin{array}{c}\text { Dificuldades na } \\
\text { Implementação da Política }\end{array}$ & \\
\hline & $\begin{array}{c}\text { Propostas de Soluções para } \\
\text { sanar as dificuldades }\end{array}$ & \\
\hline
\end{tabular}

Quadro 2: Categorias de Análise. Fonte: Dados da pesquisa. 
Quando reconhecidos e certificados pela SETUR, os circuitos turísticos passam a figurar como região prioritária para a implantação de programas de desenvolvimento do turismo, tais como obras de infraestrutura, sinalização turística, saneamento básico, formatação de cursos de qualificação de mão-de-obra local, inclusão em campanhas de divulgação e marketing, viabilização para a participação em feiras e eventos nacionais e internacionais, e apoio na aprovação de projetos de desenvolvimento turístico regional, via Fórum Estadual de Turismo, que objetiva a captação de verbas do MTur (SETUR, 2010).

A administração dos circuitos turísticos é realizada por uma entidade sem fins lucrativos, com autonomia administrativa e financeira, regida por um estatuto e formada por membros da sociedade civil e do poder público e, ainda, por um profissional (gestor) contratado para executar as ações necessárias. Sua manutenção se dá por meio do pagamento de taxas de adesão e contribuições mensais dos seus membros (SETUR, 2010).

\section{Categoria 02-Avaliação da Política}

Esta categoria tem por objetivo avaliar a Política de Circuitos a partir da percepção dos agentes estratégicos. A seguir, apresenta-se as subcategorias de análise, as quais já foram apresentadas na Figura 01.

\section{Resultados Favoráveis}

O principal resultado favorável da Política, citado por 22 entrevistados, foi a integração dos municípios para trabalhar o turismo de forma regional, unindo esforços para desenvolverem suas potencialidades turísticas, conforme pode ser evidenciado na fala de C2"Para mim, as questões favoráveis são as óbvias, no sentido que você trabalha uma região e não um município, então, através da região, você tem condições de desenvolver mais municípios, de forma mais igual, mais igualitária, de forma cooperada".

Outro resultado relevante na percepção de seis entrevistados foi a melhoria na relação com o Estado, especificamente com a SETUR, já que, desde a criação da Política, representantes dos circuitos têm tido a oportunidade de participar de discussões sobre os rumos da Política. Ademais, os municípios passam a ter um maior acesso a informações sobre o turismo, uma vez que os gestores dos circuitos estão sempre trocando informações com outros gestores, participando de encontros, reuniões e eventos promovidos pela SETUR, onde são discutidos, em conjunto, os rumos do setor. Assim, os circuitos podem se beneficiar, sempre que possível, das oportunidades existentes. Tal constatação pode ser observada na fala de C14: “(...) hoje a gente senta com o Estado, igual a gente esteve em Uberlândia semana passada, a gente senta praticamente com o estado inteiro e discute uma política de turismo, para o Estado".

Para três entrevistados, o próprio fato de os municípios, a partir do trabalho de mobilização e sensibilização realizado pela SETUR, se atentarem para as suas potencialidades turísticas e enxergarem uma oportunidade de se desenvolverem por meio dessa atividade, também é considerado positivo, pois tem gerado maior entendimen- to e engajamento dos municípios para promoverem o potencial turístico existente. Dessa forma, para C34: "Favorável foi o despertar, a mobilização e organização que foi feita nas regiões seja por parte da SETUR, seja por parte das próprias entidades, associações, que mobilizaram e sensibilizaram as pessoas nos lugares".

Outro resultado positivo apontado por dois entrevistados foi o aumento do fluxo turístico e a permanência do turista na região. Apesar de não haver pesquisas estatísticas que revelem esse aumento, segundo os entrevistados, é possível perceber um maior fluxo de turistas na região e, dados os diferentes produtos turísticos que são oferecidos (principalmente dentro de roteiros turísticos), também uma maior permanência e conseqüentemente maior gasto do turista, como aponta C19 ao ser questionado sobre os resultados da Política: “(...) permanência do turismo na região, aumento do fluxo e permanência de turistas na região, e o turista permanecendo aqui, ele roda mais a cadeia produtiva".

Dois entrevistados também relataram que a descentralização da gestão do turismo é um ponto favorável, visto que propiciou maior autonomia para cada região planejar o seu desenvolvimento turístico, como apontado por C31, quando perguntado sobre os pontos positivos da Política: "Descentralização da Política Pública de Turismo, integração regional e autonomia para planejar o desenvolvimento turístico".

Ainda, dois entrevistados consideram que, a partir da Política, houve uma interiorização da atividade turística, permitindo que municípios sem aparente tradição turística também pudessem desenvolvê-la, assim como destacado por C9: "Eu acho que favoráveis a visibilidade dos municípios menores que não eram destacados em Minas Gerais. Por estarem integrados aos circuitos".

Além desses resultados, outros foram apontados de forma específica por alguns circuitos, quais sejam: o próprio fato de se criar uma política pública para a gestão da atividade turística em Minas Gerais; desenvolvimento econômico e social das localidades; fortalecimento da atividade turística; aumento da força para a captação de recursos; maior mobilização para o desenvolvimento do turismo; orientação de gestão focada em mercado turístico; autonomia para planejar o desenvolvimento turístico da região; maior Organização do Estado; maior organização dos Municípios; melhoria dos Municípios que já eram conhecidos; ICMS turístico; convênios com a SETUR; e desconcentração da oferta turística. O Quadro 3 a seguir apresenta uma síntese dos principais resultados apresentados.

Dessa forma, considera-se que a Política tem conseguido apresentar resultados bastante significativos, pois, por meio de um trabalho conjunto entre os agentes da SETUR e agentes dos circuitos, foi possível organizar a atividade turística no Estado, fazendo com que todos os municípios mineiros pudessem participar, ainda que em graus diferentes de envolvimento, de uma política pública de turismo. Esta organização também se deu por parte dos circuitos. Ademais, a desconcentração da oferta também 


\begin{tabular}{|l|c|}
\hline \multicolumn{1}{|c|}{ Resultados favoráveis } & № de respondentes \\
\hline $\begin{array}{l}\text { Integração dos Municípios para o } \\
\text { desenvolvimento da região (associação, } \\
\text { cooperação) }\end{array}$ & 22 \\
\hline $\begin{array}{l}\text { Oportunidade de discutir com o Estado a } \\
\text { Política de Turismo }\end{array}$ & 6 \\
\hline Despertar para o turismo & 3 \\
\hline Aumento do fluxo turístico & 2 \\
\hline Descentralização de recursos & 2 \\
\hline $\begin{array}{l}\text { Maior visibilidade de municípios menores que } \\
\text { não eram destacados no setor turístico }\end{array}$ & 2 \\
\hline
\end{tabular}

Quadro 3: Principais Resultados Favoráveis da Política de Circuitos Turísticos. Fonte: Dados da pesquisa

é positiva na medida em que municípios com potencial turístico antes inexplorado, a partir da Política, têm conseguido, ainda que não na mesma proporção dos destinos já consolidados, se destacarem e atraírem mais turistas.

\section{Resultados Desfavoráveis}

De acordo com onze entrevistados, a sustentabilidade financeira dos circuitos, por meio de mensalidades de prefeituras, tem representado um grande problema para estes, visto que muitos municípios não conseguem se manter adimplentes e os circuitos, por, na maioria das vezes, não terem outra fonte de renda, acabam encontrando dificuldades para se manter em funcionamento. Para estes entrevistados, a SETUR deveria dar condições para que os circuitos consigam se manter em funcionamento, como por exemplo, oferecendo infraestrutura básica e remunerando os gestores, visto que estes, constantemente, além de atender demandas do próprio circuito, também têm demandas da SETUR, que justamente devido a baixo orçamento, delega funções para os circuitos, sem, contudo, destinar recursos para tal, conforme mencionado por C21:

Como ponto negativo, é que, por ser um programa de regionalização que foi estipulado pelo governo, além de todos os recursos descentralizados, de ações dirigidas para essas instâncias, governanças, que trabalham pra eles entre aspas, deveria ser feito um estudo para ajudar na sustentabilidade de cada região. Porque tem muito circuito aí que ta morrendo por falta de verba.

Oito entrevistados consideraram que a Política tem beneficiado mais, com ações e recursos financeiros, os circuitos mais desenvolvidos, que já tinham o turismo fortalecido. Logo, esses se tornam mais profissionais e mais competitivos, fazendo com que haja dificuldades em desconcentrar a oferta turística. Ao ser perguntado sobre os resultados desfavoráveis da Política, C28 afirmou: (...) distribuição de recursos, que às vezes inviabiliza bons projetos e bons produtos porque tem que se investir sempre naqueles que já estão em evidência. Então isso impede que os que estão em potencial venham se tornar um produto tão bom quanto e se desenvolver.

Dois entrevistados argumentaram que ainda há dependência dos circuitos em relação à SETUR e que falta ridículo" (...)". autonomia na gestão dos circuitos, conforme evidenciado por C1: "A execução da política, falta de autonomia para os circuitos (...) a gente fica meio esmagado entro o Estado e o Município, mas o poder de governança é às vezes um pouco questionado"

Dois entrevistados também consideram que a SETUR possui um orçamento de baixo valor e, em consequência, poucos recursos ainda são destinados aos circuitos, como mencionado pelo entrevistado $\mathrm{C} 26$ : "O orçamento é muito pequeno (...) às vezes na reunião eles falam os valores que eles passam e, em princípio, parece ser um valor até substancial, só que na hora que você

divide isso pelo número de municípios que participam, é

Dois entrevistados argumentam que a SETUR é bastante burocrática em relação às cobranças e exigências junto aos circuitos e isso também é considerado um ponto negativo da Política. Assim, conforme apontado por C10: "a questão ruim do negócio do Circuito da SETUR, com a SETUR, é a burocratização. É uma burocratização, uma papelada que manda, um monte de e-mail que manda

Dois entrevistados consideram que o turismo é tratado com certo descaso pelos prefeitos, considerando que este não se trata de uma prioridade para alguns municípios, conforme destacado por C16: “(...) é o descaso do próprio Governo Municipal (...) é só secretaria de obra trabalhando e acham que isso aí é a cara do município, que isso aí vai encher os olhos do turista, mas se ver de uma outra forma, começar a estudar o que é turismo mesmo, eu acredito que muda".

Ainda, de acordo com dois entrevistados, a SETUR exige muito dos circuitos, demanda ações, mas não oferece todo o apoio de que eles necessitam (como o apoio financeiro por exemplo), conforme evidenciado por C31: "Existem muitas cobranças e pouco apoio financeiro do poder público federal e estadual na estruturação, operacionalização, roteirização e promoção dos circuitos".

Especificamente, outros resultados desfavoráveis também foram apontados pelos entrevistados, tais como: falta de reconhecimento das prefeituras de que o circuito é uma instância de governança; falta de comprometimento e envolvimento dos associados; rivalidade entre os municípios de um mesmo circuito; tendência das prefeituras em acreditar que vão continuar dentro do programa, não importando o que acontecer; inexistência de lei que legitime a participação dos municípios no circuito; dificuldades de compreensão do desenvolvimento turístico quando ocorrem mudanças na gestão municipal; pouca divulgação e esclarecimentos oficiais sobre a Política de Circuitos Turísticos para municípios; trade turístico e comunidades; falta visita de técnicos e profissionais do turismo nos municípios para entender a sua fase de desenvolvimento e as suas demandas principais; diferentes níveis de comprometimento e envolvimento das prefeituras; mesmas cobranças para circuitos diferentes; e falta de preparação 
dos circuitos para receberem a Política. O Quadro 4 a seguir apresenta-se uma síntese dos principais resultados apresentados.

Percebe-se que, como a SETUR ainda atua pouco em circuitos menos desenvolvidos, estes passam a ser meros integrantes da Política, sem, contudo, se beneficiarem dela. Constata-se também que, embora a SETUR trabalhe de forma descentralizada, alguns circuitos ainda não conseguem trabalhar de forma autônoma, conforme se esperava quando da criação dos circuitos. Disso decorre que a SETUR precisa delegar mais e, na medida do possível, transferir maior aporte de recursos para que os circuitos consigam se

\begin{tabular}{|l|c|}
\hline \multicolumn{1}{|c|}{ Resultados desfavoráveis } & № de respondentes \\
\hline $\begin{array}{l}\text { Dificuldade de manutenção financeira dos } \\
\text { circuitos }\end{array}$ & 11 \\
\hline $\begin{array}{l}\text { Maior apoio às regiões turísticas } \\
\text { tradicionalmente mais conhecidas }\end{array}$ & 8 \\
\hline Dependência em relação à SETUR & 2 \\
\hline Baixo orçamento da SETUR & 2 \\
\hline Burocratização da SETUR & 2 \\
\hline O turismo não é considerado prioridade & 2 \\
\hline $\begin{array}{l}\text { Existem muitas cobranças e demanda de } \\
\text { ações, mas pouco apoio }\end{array}$ & 2 \\
\hline
\end{tabular}

Quadro 4: Resultados Desfavoráveis da Política de Circuitos Turísticos. Fonte: Dados da pesquisa manter.

Observa-se, ainda, que a SETUR descentraliza muitas ações para os circuitos, mas, dada a falta de recursos, sejam humanos ou financeiros destes, muitos não têm como atendê-las. Além disso, a burocratização para atender as exigências da SETUR para que os circuitos sejam contemplados com a Política deve ser revista ou os circuitos devem ser melhores instruídos para atendê-las, visto que de nada adianta a disponibilização de ações ou de recursos se os circuitos não conseguirem ser contemplados.

\section{Dificuldades na Implementação da Política}

De acordo com vinte entrevistados, uma grande dificuldade que os circuitos vêm enfrentando é com relação à sustentabilidade financeira. Em grande parte dos circuitos, muitas prefeituras estão inadimplentes e como, na maioria das vezes, estes não recebem apoio financeiro de outras fontes, acabam tendo dificuldades para se manterem em funcionamento. Para os entrevistados, a SETUR deveria dar mais condições para os circuitos trabalharem, como evidenciado por C12: " O Governo não dá condições pra trabalhar e quer que a gente assuma isso. Esse assumir acaba caindo na questão financeira (...)".

Conforme oito entrevistados, outra dificuldade é a falta de envolvimento e comprometimento dos associados com as responsabilidades assumidas, como mencionado por C9: "Acho que a falta de compromisso (...) dos que estão realmente assumindo essa. Até mesmo vamos dizer assim da diretoria, de acreditar realmente no potencial, no quê a gente está fazendo, de qual é o nosso trabalho".

Para seis entrevistados, também ainda falta conscientização por parte das prefeituras e da iniciativa privada sobre a importância do turismo e sobre as potencialidades do setor, o que acaba fazendo com que estes não se engajem para o desenvolvimento turístico da região, como salienta C15: "a maior dificuldade, que eu até já falei, é a falta de entendimento dos gestores públicos, dos empresários, com relação à atividade turística".

Outra dificuldade apontada por cinco entrevistados diz respeito à sensibilização da comunidade, ou seja, a dificuldade em fazer com que as comunidades entendam o papel do circuito e se envolvam com as ações propostas por estes, conforme mencionado por $\mathrm{C} 1$ quando questiona- do sobre as dificuldades: “(...) conseguir sensibilizar todo mundo e unificar o discurso (...)".

Quatro entrevistados também consideram como dificuldade a captação de associados da iniciativa privada, uma vez que estes ainda acreditam que a gestão do turismo é de responsabilidade do poder público, conforme observado por C10 “(...) trazer a iniciativa privada, que a iniciativa privada acha que isso é função do poder público, entendeu? Esse é um outro problema também".

Outra dificuldade apontada por três entrevistados é a ausência do gestor em alguns circuitos, fazendo com que a gestão destes acabe ficando a cargo do presidente e/ou membros da diretoria. Conforme mencionado por C36, a presença do gestor poderia fazer com que o circuito tivesse uma melhor atuação: "ausência do gestor que eu acho que hoje é tudo assim para a gente. Eu acho que a gente poderia até pensar mais, ousar mais, isso não justifica a gente ter um planejamento falho, mas eu acho que a figura do gestor hoje para nós viabilizaria muito mais ações, muito mais planejamento".

A sobrecarga de funções atribuídas ao gestor, em virtude do reduzido número de funcionários, também foi mencionada como uma dificuldade para dois entrevistados, o que faz com que grande parte das atividades a serem desenvolvidas fique a cargo de uma ou duas pessoas, como citado por $\mathrm{C} 2$ :

(...) não existe uma equipe hoje, muito por uma questão financeira, não existe uma equipe responsável por cada setor. E aqui acaba centralizando muito, não só no gestor, mas principalmente no diretor executivo também que a questão da decisão está muito centralizada em uma pessoa só (...).

De forma específica, outras dificuldades foram apontadas pelos entrevistados, tais como: dependência do circuito em relação a gestões passadas; falta de planejamento, divergências e conflitos de interesse; falta de autonomia na gestão do circuito; política em excesso; pouca mobilização das comunidades; falta de profissionalismo nas prefeituras; ausência de equipe técnica, equipamentos, sede e veículo próprio que garantam as atividades mínimas demandadas pelo associados; ausência de representantes 
municipais com autonomia para executar ações no município; inexistência de um setor de criação de projetos para mobilização de recursos; falta de apoio técnico personalizado da SETUR; falta de rigor do Estado em relação à aplicação dos recursos financeiros no turismo; descontinuidade dos governos municipais; não cumprimento do estatuto pelos associados; ausência de uma rota no circuito turístico; prioridade de alguns circuitos no que diz respeito aos investimentos públicos; pouco apoio para o circuito trabalhar a promoção e o marketing turístico do circuito.

Logo, identifica-se que a maior dificuldade enfrentada pelos circuitos, assim como pela SETUR, é a financeira. Dessa forma, como a SETUR trabalha com um baixo orçamento e os circuitos têm que se manter com a mensalidade paga pelas prefeituras, que muitas vezes estão inadimplentes, torna-se necessário que os circuitos ampliem seu número de associados, principalmente da iniciativa privada. Contudo, dada a dificuldade dos circuitos em conscientizar esses associados da iniciativa privada, torna-se imprescindível que a SETUR faça um trabalho de sensibilização no Estado, demonstrando a importância do turismo e das vantagens que ele pode trazer aos envolvidos. O Quadro 5 a seguir sintetiza as principais dificuldades apresentadas.

\begin{tabular}{|l|c|}
\hline \multicolumn{1}{|c|}{ Dificuldades } & № de respondentes \\
\hline Sustentabilidade Financeira & 22 \\
\hline $\begin{array}{l}\text { Falta de comprometimento com as } \\
\text { responsabilidades assumidas pelos membros } \\
\text { dos circuitos }\end{array}$ & 8 \\
\hline $\begin{array}{l}\text { Falta de conscientização das prefeituras e da } \\
\text { iniciativa provada sobre a importância do } \\
\text { turismo }\end{array}$ & 6 \\
\hline Sensibilização da Comunidade & 5 \\
\hline Captação de associados da iniciativa privada & 4 \\
\hline Ausência de gestor & 3 \\
\hline Número reduzido de funcionários & 2 \\
\hline
\end{tabular}

Quadro 5: Dificuldades enfrentadas pelos circuitos turísticos. Fonte: Dados da pesquisa

\section{Propostas de Soluções para Sanar as Dificuldades}

Sete entrevistados apontam que, para superar a dificuldade de se ter somente associados do poder público, os circuitos deveriam captar novos associados, principalmente da iniciativa privada, para garantir a continuidade dos circuitos mesmo com as trocas de governo. Além disso, essa captação também poderia minimizar a dificuldade financeira, visto que aumentaria o valor arrecadado com as mensalidades, conforme apresentado por C36: "a gente tem que ter outros recursos para poder manter o Circuito e aí eu acho que dessa forma a gente teria condições de contratar um gestor, porque, também, a gente sabe que o trabalho é árduo e a gente não quer também contratar com um salário baixo, a gente quer algo razoável (...).

Seis entrevistados também consideram que o ICMS turístico também poderá estimular a estruturação do setor turístico nos municípios, não só do ponto de vista fi- nanceiro, mas principalmente pelo fato de organizar a atividade, visto que a distribuição do ICMS turístico tem por base o nível de envolvimento das prefeituras no processo de desenvolvimento turístico local e de adesão às políticas de turismo dos Governos Estadual e Federal. Além disso, algumas ações pontuais tem que ser executadas para fazerem jus aos benefícios dessa nova proposta de redistribuição de receita. Assim, o ICMS, além de possibilitar uma nova fonte de receita para os municípios, também poderia ajudar a solucionar o problema de falta de organização dos municípios para desenvolver a atividade turística, conforme mencionado por C14:

Eu acredito que, com o ICMS turístico, eu acho que a gente vai conseguir resolver algumas coisas, o município já vai ter um plano de turismo, já vai começar a sentir o que é o turismo no município, na região, então eu acho que isso já vai dar, não é o que vai resolver o problema, mas acho que já vai começar um progresso (...) (C14).

Cinco entrevistados acreditam que a SETUR deve destinar mais recursos financeiros para que os circuitos superem as dificuldades de se manterem em funcionamento, conforme apontado pelo entrevistado C3: "a SETUR eu acho que tem que apoiar mais projetos financeiros, mais a motivação mesmo nos Circuitos, que eu acho que o primeiro passo que começa a alavancar o negócio é com dinheiro, porque sem dinheiro a gente não consegue (...).

Quatro entrevistados acreditam que a SETUR deveria desenvolver mais ações de sensibilização junto aos associados (do poder público e da iniciativa privada) para demonstrar a importância do trabalho realizado pelos circuitos. Dessa forma, esta sensibilização poderia contribuir para superar a dificuldade de falta de envolvimento dos associados e descrédito desses com relação ao circuito, conforme apontado por C6: “(...) eu acho que aí é o papel que a SETUR tem que fazer de sensibilizar, de mobilizar e de mostrar para o poder público principalmente que é o grande parceiro da gente, da importância de não só de estar, mas de valorizar mesmo e de integrar mesmo na coisa".

Três entrevistados também mencionaram como possível solução para a Política uma proposta feita por um dos gestores durante um encontro de presidentes e gestores organizados pela SETUR, que segundo C21 corresponde a: "que a cada 1 real que a prefeitura por no circuito de mensalidade, que ela receba em dobro no final do ano em obras, em ações". Para os entrevistados, essa proposta representa um meio de estimular o pagamento das mensalidades por parte das prefeituras a fim de minimizar os problemas de inadimplência,

Ainda, dois entrevistados consideram que se o Governo estadual remunerasse o gestor, todos os circuitos contariam com sua presença, visto que os que não tem 
deve-se a falta de recursos para bancar os salários. Assim, para os entrevistados, essa remuneração ajudaria os circuitos a superarem parte de suas dificuldades financeiras, e, ainda, garantiria a presença constante de gestores nos circuitos. O entrevistado C34 apresenta uma maneira de viabilizar essa remuneração: “(...) se o gestor fosse contratado via consultoria e empresa terceirizada, que emite nota fiscal, prestador de serviço que vai saber gerar recurso pro Estado, eu acho que isso seria uma solução pros circuitos (...)"

Especificamente, os entrevistados também apresentaram as seguintes sugestões: que no circuito tenha uma equipe, cada um responsável por um setor; busca de novos recursos, seja humanos ou financeiros; maior envolvimen- cientizar todo o Estado sobre a importância da Política e para a falta de envolvimento e comprometimentos dos associados foram pouco mencionadas.

Diante do exposto, acredita-se que circuitos também poderiam realizar encontros e promover espaços de discussão com as comunidades de forma a integrá-la mais aos circuitos. Dessa forma, não ficaria a cargo somente dos representantes dos municípios junto aos circuitos o papel de sensibilizar suas comunidades, visto que muitas vezes estes mesmos não estão muito envolvidos e comprometidos com o circuito.

O Quadro 6 a seguir sintetiza as principais propostas dos entrevistados.

to do trade e da comunidade; renovação da gestão do circuito; maior divulgação dos resultados do circuito; criação de câmaras temáticas para ações pontuais; criação de grupos de trabalho; capacitação dos representantes dos municípios; maior diálogo com os associados; maior envolvimento por parte dos municípios e empresários associados nas reuniões e tomadas de decisão; promover a profissionalização dos gestores das associações; garantir o pagamento das mensalidades dos associados de forma permanente; participação mais ativa da

\begin{tabular}{|c|c|}
\hline \multicolumn{1}{|c|}{ Principais Propostas } & № de respondentes \\
\hline \multicolumn{1}{|c|}{ Capitação de novos associados } & 7 \\
\hline Maior destinação de recursos & 5 \\
\hline ICMS Turístico & 5 \\
\hline Maior sensibilização por parte da SETUR & 4 \\
\hline a cada 1 real que a prefeitura por no circuito de \\
dade, que ela receba em dobro no final do ano em \\
obras, em ações
\end{tabular}

Quadro 6: Principais propostas dos agentes dos circuitos para sanar as dificuldades dos circuitos
SETUR referente à cobrança dos municípios dentro dos circuitos; elaboração e envio de projetos para editais; e criação de um processo educativo para o turismo.

Ainda, os entrevistados apontaram: visitas frequentes aos municípios com a presença do gestor; implantação de um setor de elaboração de projetos e mobilização de recursos; criação de rotas turísticas; concurso para gestor; criação de grupos de trabalho; aumento do valor das mensalidades; visita de técnicos da SETUR aos municípios ou sede do circuito para observar os problemas, definir as necessidades e executar as ações de melhoria junto com o povo e lideranças locais; fiscalização e punição dos prefeitos e municípios que não investirem no turismo de forma eficiente; trabalhar o processo de sucessão dos circuitos; maior investimento do governo em ações estruturadoras dos circuitos (roteirização, sinalização, pesquisa de demanda, capacitação, divulgação e promoção, sensibilização etc.); apoio igualitário aos circuitos, por parte do Governo do Estado; manutenção das atividades diárias do circuito; e disponibilização de um veículo próprio para os circuitos.

Diante dessas propostas, identifica-se que os entrevistados consideram mudanças não somente por parte da SETUR, mas também internamente nos circuitos. Logo, percebe-se que as soluções para os fatores ainda limitantes da Política podem emergir da base.

Contudo, percebe-se que as propostas apresentadas visam solucionar mais os aspectos financeiros nos circuitos. Por outro lado, propostas para sensibilizar as comunidades dos municípios integrantes dos circuitos, para cons-

\section{Conclusão}

Conforme proposto, o presente estudo avaliou a Política de Circuitos Turísticos em Minas Gerais, considerando seus resultados favoráveis e desfavoráveis, dificuldades e propostas para sanar tais dificuldades.

$\mathrm{Na}$ percepção de agentes estratégicos, os principais resultados favoráveis se traduzem na integração dos municípios para o desenvolvimento da região (associação, cooperação); no aumento do fluxo turístico e permanência do turista nos destinos; no despertar e na conscientização para o turismo; na oportunidade de diálogo com o Estado; na descentralização de recursos; e na maior visibilidade de municípios menores que não eram destacados no setor turístico.

Por outro lado, os principais resultados desfavoráveis estão associados à dependência dos circuitos em relação à SETUR, conjugada com seu baixo orçamento e burocratização, o que dificulta a manutenção financeira dos circuitos; além da falta de prioridade dada ao turismo, com maior apoio aos circuitos mais desenvolvidos, gerando-se competitividade e desigualdades.

Os resultados desfavoráveis são derivados das dificuldades enfrentadas pelos circuitos na execução da Política, externalizadas pela dificuldade financeira; baixa sensibilização da comunidade; reduzido número de funcionários no circuito e sobrecarga do gestor; falta de conscientização das prefeituras sobre a importância do turismo; escasso envolvimento e comprometimento dos associados com o 
circuito; dificuldades de trazer a iniciativa privada para o circuito; além da ausência de gestor.

Conclui-se diante do exposto, que apesar dos desafios apontados pelos entrevistados, existe a perspectiva de continuidade da Política, considerando, sobretudo, a sua capacidade de potencializar atrativos turísticos, de mobilizar as comunidades locais para o desenvolvimento da atividade e de captar recursos financeiros e humanos.

Como a priori não se identificou mecanismos específicos para avaliação da Política analisada, entende-se que os resultados encontrados nesse estudo podem se revelar importantes, uma vez que, além de apontar a configuração atual da Política, também apresentam propostas de melhorias, de modo a subsidiar decisões futuras sobre as ações a serem desenvolvidas a curto e longo prazo para a sua continuidade.

Como futuras pesquisas, sugere-se a replicação desta mesma análise de forma estratificada por regiões de Minas Gerais, de forma a identificar se as especificidades de cada uma impactam nos resultados da Política. Além disso, pode-se agrupar os circuitos conforme o nível de gestão (profissionalização) em que se encontram confrontando com os resultados obtidos, de modo a identificar se circuitos mais profissionais apresentam melhores resultados.

\section{Referências bibliográficas}

Bardin, L. 2002 Análise de Conteúdo. Lisboa, Portugal: Edições 70. Barretto, M.; Burgos, R.. Frenkel, D..

2003 Turismo, políticas públicas e relações internacionais. São Paulo: Papirus.

Belloni, M. e S.

2003 Metodologia de avaliação em políticas públicas: uma experiência em educação profissional. $3^{\mathrm{a}} \mathrm{ed}$. São Paulo:Corte.

Beni, M. C.

1998 Análise estrutural do turismo. 2.ed. São Paulo: SENAC.

Cohen, E.; Franco, R.

2004 Avaliação de Projetos Sociais. Petrópolis:Vozes.

Costa, F. L. da; Castanhar, J. C.

2003 "Avaliação de programas públicos: desafios conceituais e metodológicos". Revista de Administração Pública, 37(5): 962-969.

Cruz, R. de C. A. da.

2001 Política de turismo e território. São Paulo: Contexto. Draibe, S. M.

2001 "Avaliação de implementação: esboço de uma metodologia de trabalho em políticas públicas". In: Barreira M. C. R. N.; Carvalho, M. C. B. (Orgs.). Tendências e perspectivas na avaliação de políticas e programas sociais. São Paulo: IEE/PUC-SP. Pp. 13-42.

Faria, C. A. P de.

2003 "Idéias, Conhecimento e Políticas Públicas: um inventário sucinto das principais vertentes analíticas recentes". Revista Brasileira de Ciências Sociais, 18(51): $21-29$.
Fernandes. A. S. A.

2007 "Políticas Públicas: Definição evolução e o caso brasileiro na política social”. In Dantas, Humberto e Junior, José Paulo M. (orgs). Introdução à política brasileira, São Paulo: Paulus.

FJP - Fundação João Pinheiro

2009 Impacto do turismo nas finanças municipais nas regiões turísticas do Brasil. Centro de Estudos de Políticas Públicas. Belo Horizonte.

MTUR - Ministério do Turismo.

2011 "Notícia: Recorde de receita pelo turismo". "Dados e fatos. Disponível em: http://www.dadosefatos.turismo.gov.br/dadosefatos/geral_interna/noticias/detalhe/20110126_1.html. Acesso em 30/01/2011.

MTUR - Ministério do Turismo.

2011. "Glossário de Turismo". Disponível em: http://www. braziltour.com/site/br/dados_fatos/conteudo/lista_alfabeto.php?pagina $=3 \&$ in_secao $=387 \&$ busca $=T$. Acesso em $10 / 11 / 2010$.

OMT - Organização Mundial do Turismo

2001 Introdução ao Turismo. São Paulo: Roca.

OMT - Organização Mundial do Turismo

2005 Introdução à metodologia da pesquisa em turismo. São Paulo: Roca,

Saravia, E.

2006. "Introdução à teoria da política pública". In: Saravia, E. e Ferrarezi, E. (org.). Políticas públicas: coletânea. Brasília: ENAP. Vol. 1. P. 21-43.

SETUR - Secretaria de Estado do Turismo.

2010 "Legislação. Disponível em: http://www.turismo. mg.gov.br/institucional/legislacao. Acesso em: $10 \mathrm{de}$ janeiro de 2010 .

Recibido:

$08 / 02 / 2011$

Reenviado:

$02 / 09 / 2011$

Aceptado:

$15 / 10 / 2011$

Sometido a evaluación por pares anónimos 